\title{
Children with Special Health Care Need's Association of Passive Tobacco Smoke Exposure and Dental Caries: 2007 National Survey of Children's Health
}

\section{R Constance Wiener*}

Dental Practice and Rural Health, School of Dentistry, Department of Epidemiology, School of Public Health, West Virginia University, USA

\begin{abstract}
Purpose: The purpose of this study was to determine a relationship between passive tobacco smoke exposure (secondhand and third hand tobacco smoke exposure) and dental caries in Children with Special Health Care Needs (CSHCN) ages 0-17 years.

Method: This study used data from the 2007 National Survey of Children's Health involving 17,901 CSHCN. Telephone survey data were used to determine recent caries experience and passive tobacco smoke exposure (secondhand and third hand tobacco smoke exposure). Recent caries was defined as a positive response to if CSHCN had "decayed teeth or cavities within the past 6 months." Passive smoke was defined as a positive response to if someone in the household used cigarettes, cigars, or pipe tobacco.
\end{abstract}

Results: A statistically significant relationship was determined between passive tobacco smoke exposure and recent caries in CSHCN (adjusted odds ratio: 1.23 (95\% Cl: 1.02, 1.50; p-value= 0.0352).

Conclusion: A positive independent association of passive tobacco smoke exposure and dental caries was determined in Children with Special Health Care Needs (CSHCN).

Keywords: Tobacco; Abnormalities; Bacterial colonization, Allergies

\section{Introduction}

The U.S. Maternal and Child Health Bureau's Division of Services for Children with Special Health Care Needs (CSHCN) identifies CSHCN as children having or having the risk of psychological abnormalities (developmental, behavioral or emotional) as well as children having or having the risk of chronic physical conditions/diseases beyond the typical needs of children in general [1]. There are more than 14.1 million U.S. children who are CSHCN [2], and more than $20 \%$ of U.S. families have CSHCN [3]. Identifying children as CSHCN, rather than by having specific psychological abnormalities/physical conditions, has improved health care delivery programs [3], and has resulted in a national surveillance, the National Survey of Children's Health. From the surveillance, it is known that CSHCN are at increased risk of depression, inactivity, and injury [2]. Additionally, tobacco smoke exposure is greater in CSHCN [2].

Tobacco smoke exposure may be primary or passive. Primary smoke exposure is the exposure to the person smoking tobacco. Passive smoke exposure may occur as Second Hand Smoke (SHS) (the sidestream smoke of the burning tobacco and mainstream smoke exhaled by the smoker [4]) or Third Hand Smoke (THS) (the residue, pollutant, persistent tobacco contaminant on clothes, skin, hair, furniture, carpet, etc. [5]). Myriad studies indicate tobacco is associated with poor health. However the association between passive smoke exposure and dental caries is controversial. Some studies indicate such an association exists in pre-school children [6-11], in older children [12,13], and in animal models [14]; while two reviews suggested the evidence is weak or of poor quality [15,16]; and other studies failed to find an association [17-19].

Dental caries is a complex, multi-factorial biofilm-induced disease involving the endogenous oral bacteria and the demineralization/ remineralization process of an affected tooth in which the balance is shifted to greater tooth demineralization. There are several theoretical bases for considering passive smoke as a factor in the etiology of caries. Vitamin C levels were found to be decreased in children exposed to passive smoke, and low levels of Vitamin C are associated with decreased immune function and Streptococcus Mutans growth
[16]. Passive smoke is associated with decreased saliva and reduced buffering capacity in children exposed to passive smoke, which may reduce remineralization, allow for less bacterial clearance, and allow enhanced bacterial colonization [16]. Heavy metals, such as cadmium, in passive smoke may be independent risk factors for caries [16].

It is important to identify the role of passive smoking and dental caries. The purpose of this study is to examine the relationship of passive smoking (SHS and THS) and dental caries in CSHCN. CSHCN are a vulnerable population in which the exposure to passive smoke may be particularly detrimental. The research hypothesis is that CSHCN who are exposed to passive smoking (SHS and THS) by having a person in the household who used cigarettes, cigars, or pipe tobacco, will have greater odds of having caries within the previous 6 months than CSHCN who are not exposed to passive smoke. The results of this study will add to the literature current information about the role of tobacco smoke exposure and caries development in the vulnerable population of CSHCN, whereas previous studies have worked with children who did not have SHCN. Also, the results will add to the weight of evidence in support of or against the role of tobacco smoke and caries in the current literature.

\section{Methods}

The data used in this study were public use, de-identified data

*Corresponding author: R Constance Wiener, Dental Practice and Rural Health, School of Dentistry, Department of Epidemiology, School of Public Health, West Virginia University, PO Box 9448104 Health Sciences center addition, Morgantown, WV 26506, USA, Tel: 304 581-1960; Fax: 304 293-8561; E-mail: rwiener2@hsc.wvu.edu

Received July 22, 2013; Accepted August 23, 2013; Published August 27, 2013

Citation: Wiener RC (2013) Children with Special Health Care Need's Association of Passive Tobacco Smoke Exposure and Dental Caries: 2007 National Survey of Children's Health. J Psychol Abnorm Child 2: 104. doi:10.4172/2329-9525.1000104

Copyright: (c) 2013 Wiener RC. This is an open-access article distributed under the terms of the Creative Commons Attribution License, which permits unrestricted use, distribution, and reproduction in any medium, provided the original author and source are credited. 
resulting in non-human subject secondary data analysis research. Researchers from the National Center for Health Statistics (NCHS) of the Centers for Disease Control and Prevention conducted the 2007 National Survey of Children's Health, a national telephone survey of 91,642 participants (between 1725 and 1932 participants of Columbia) with in each state and the District IRB approval from the CDC [20]. Survey weights were applied to adjust for the state-specific population characteristics of the non-institutionalized children age 0-17 years [20]. Detailed methodology is available from the NSCHS website: http:// www.cdc.gov/nchs/data/series/sr_01/sr01_055.pdf.

\section{Identification of CSHCN}

The NSCHS provided a yes/no variable to identify CSHCN. The variable was derived by the researchers at NSCHSusing the CSHCN Screener ${ }^{\odot}$ In summary, for a child to be categorized as CSHCN, he or she had an ongoing behavioral, medical, or health condition which lasted or was expected to last 12 months or longer. Additionally at least one of the following on-going conditions based upon a behavioral, medical or health condition had to be met: 1) emotional, developmental, or behavioral problems in need of counseling; 2) use of more services than other children for mental health care, educational support, or medical care; 3 ) use of prescription medications for the behavioral, medical, or health condition; 4) use of therapies (speech therapy, occupational therapy, physical therapy, etc.) for the behavioral, medical, or health condition; or 5) limitations due to behavioral, medical, or health conditions.

\section{Recent caries definition}

A participant was asked about his or her child's dental status with the question: "To the best of your knowledge, did [child's name] have decayed teeth or cavities within the past 6 months?" In this study, the respondents who answered affirmatively were classified as having recent caries, and the respondents who answered negatively were classified as not having recent caries.

\section{Passive tobacco smoke exposure definition}

The participants were asked, "Does anyone living in your household use cigarettes, cigars, or pipe tobacco?” The participants who responded affirmatively were classified as having children with passive tobacco smoke exposure (SHS or THS), and the respondents who answered negatively were classified as having children with no passive smoke exposure.

\section{Other variables}

Several other variables were considered for potential inclusion in the multivariable logistic regression, if the bivariate associations were significant. Participants provided the sex of the child (male/ female), age of the child (0-5 years, 6-11 years, 12-17 years), race/ ethnicity of the child (Hispanic, non-Hispanic white, non-Hispanic black, other), and allergy and asthma status of the child (yes/no). They also provided family income which was categorized into less than $100 \%$ of the Federal Poverty level(FPL), 100-199\% FPL, 200-399\% FPL, and $400 \%$ and above FPL. The respondent provided the child's mother's and father's educational status, categorized into highest level of education in the household (less than high school education, high school graduate, greater than high school education).Other variables with the potential to confound smoking and caries that were considered were medication use (with the potential for xerostomia), asthma, and allergies. These variables had yes/no response options for the participants.

\section{Statistical analyses}

Statistical analyses were performed using SAS software package version 5.1 (SAS Institute, Inc., Cary, NC, USA). Data were analyzed using chi square statistics and multivariable logistic regression with apriori selection of $\mathrm{p}<0.05$ as the significance level. Of the 91,642 participants, 85,913 had complete data concerning caries and household tobacco use; these participants included parents/guardians of CSHCN and children who did not have SHCN. There were 17,901 parents/ guardians of CSHCN who had complete data concerning caries and household tobacco use. The analysis included both parents/guardians of CSHCN and of children who did not have SHCN to determine the odds ratio of exposure/non-exposure of tobacco smoke and caries and as a secondary aim, the differences between the overall group and the CSHCN group as a secondary focus of the study. Bivariate analyses with Chi square were conducted, and a multivariable logistic regression model was developed. Variables with bivariate relationships not reaching significance in the chi square analysis or logistic regression (if they did not impact the passive smoke odds ratio by $15 \%$ and therefore could be considered a confounder) were not to be included in the final multivariable model.

\section{Results}

Overall, there were $48.72 \%$ females, $56.53 \%$ non-Hispanic white, $20.17 \%$ Hispanic and $14.40 \%$ non-Hispanic black. The children's age groups ( $0-5$ years, $6-11$ years, and $12-17$ years) had $29.25 \%, 34.44 \%$ and $36.31 \%$, respectively. The majority of families had a household member who had more than a high school education (67.77\%). There were $18.28 \%$ reporting a household income of less than $100 \%$ FPL; $20.88 \%$ reporting between $100-199 \%$ FPL; $31.22 \%$ reporting between $200-399 \%$ FPL and $29.62 \%$ reporting $400 \%$ and above FPL. Tobacco use was reported by $26.12 \%$, and caries within the previous 6 months was reported by $19.41 \%$.

For CSHCN, there were $40.67 \%$ females, $60.86 \%$ non-Hispanic white, $15.35 \%$ Hispanic and $16.20 \%$ non-Hispanic black. The children's age groups ( $0-5$ years, $6-11$ years, and $12-17$ years) had $18.65 \%, 38.66 \%$ and $42.69 \%$, respectively. The majority of families had a household member who had more than a high school education (68.64\%). There were $20.15 \%$ reporting a household income of less than $100 \%$ FPL; 20.78\% reporting between 100-199\% FPL; 30.58\% reporting between 200-399\% FPL and $28.49 \%$ reporting $400 \%$ and above FPL. Tobacco use was reported by $30.25 \%$, and caries within the previous 6 months was reported by $22.79 \%$. The sample descriptive statistics are presented in Table 1.

Table 2 describes the bivariate associations of caries and variables of interest. In addition to the key association of interest (caries and passive smoke exposure), other significant associations existed for race/ ethnicity, age, highest household education, and household income for CSHCN. For children, overall, asthma had a significant association with caries, but the association was not significant for CSHCN.

Table 3 provides the logistic regression for caries and passive smoke exposure. For all children, the unadjusted odds ratio for caries related to passive smoke exposure was 1.37 (95\% Confidence Interval: 1.23, 1.52; $\mathrm{p}$-value $<0.0001)$. The unadjusted odds ratio for caries related to passive smoke exposure for CSHCN was 1.35 (95\% Confidence Interval: 1.13, 1.62; $\mathrm{p}$-value $=0.0011$ ). When a model was constructed to adjust for race/ethnicity, age, and income the overall adjusted odds ratio for caries related to passive smoke was 1.27 (95\% Confidence Interval: 1.14, 1.41; p-value $<0.0001)$. For CSHCN, the adjusted odds ratio was $1.23(95 \%$ Confidence Interval: 1.02, 1.50; p-value 0.0352). 
Citation: Wiener RC (2013) Children with Special Health Care Need's Association of Passive Tobacco Smoke Exposure and Dental Caries: 2007 National Survey of Children's Health. J Psychol Abnorm Child 2: 104. doi:10.4172/2329-9525.1000104

Page 3 of 5

\section{Discussion}

The results of this study indicate that CSHCN have an independent association of recent caries (within the previous 6 months) and passive smoke (someone in the household used cigarettes, cigars, or pipe tobacco). These results are consistent with previous studies supporting such an association in children who did not have SHCN [6-11]. For example, maternal smoking was independently associated

\begin{tabular}{|c|c|c|c|c|}
\hline & \multicolumn{2}{|c|}{ Overall } & \multicolumn{2}{|c|}{$\mathrm{CSHCN}$} \\
\hline & $\mathrm{N}$ & $w t \%$ & $\mathrm{~N}$ & wt $\%$ \\
\hline & \multicolumn{2}{|c|}{85913} & \multicolumn{2}{|c|}{17901} \\
\hline \multicolumn{5}{|l|}{ Sex } \\
\hline Female & 41240 & 48.72 & 7531 & 40.67 \\
\hline Male & 44568 & 51.28 & 10352 & 59.33 \\
\hline \multicolumn{5}{|l|}{ Race/ethnicity } \\
\hline Non-Hispanic white & 58179 & 56.53 & 12548 & 60.86 \\
\hline Non-Hispanic black & 8419 & 14.4 & 1857 & 16.2 \\
\hline Hispanic & 10680 & 20.17 & 1796 & 15.35 \\
\hline Other & 7768 & 8.9 & 1546 & 7.6 \\
\hline \multicolumn{5}{|l|}{ Age } \\
\hline $0-5$ years & 22583 & 29.25 & 3002 & 18.65 \\
\hline $6-11$ years & 27504 & 34.44 & 6143 & 38.66 \\
\hline $12-17$ years & 35826 & 36.31 & 8756 & 42.69 \\
\hline \multicolumn{5}{|c|}{ Household highest education } \\
\hline Less than high school & 64567 & 8.94 & 927 & 8.94 \\
\hline High school graduate & 13261 & 23.29 & 2778 & 22.42 \\
\hline More than high school & 4979 & 67.77 & 13271 & 68.64 \\
\hline \multicolumn{5}{|l|}{ Household income } \\
\hline Less than $100 \% \mathrm{FPL}$ & 10057 & 18.28 & 2398 & 20.15 \\
\hline $100-199 \% \mathrm{FPL}$ & 14590 & 20.88 & 3101 & 20.78 \\
\hline $200-399 \%$ FPL & 29055 & 31.22 & 5820 & 30.58 \\
\hline $400 \%$ and above FPL & 32211 & 29.62 & 6582 & 28.49 \\
\hline \multicolumn{5}{|l|}{ Medication use } \\
\hline Yes & 1900 & 2.04 & 1441 & 9 \\
\hline No & 75453 & 97.96 & 12477 & 91 \\
\hline \multicolumn{5}{|l|}{ Asthma } \\
\hline Yes & 11789 & 14.34 & 6691 & 38.89 \\
\hline No & 74022 & 85.66 & 11177 & 61.11 \\
\hline \multicolumn{5}{|l|}{ Allergies } \\
\hline Yes & 16197 & 17.36 & 7112 & 37.7 \\
\hline No & 69554 & 82.64 & 12828 & 62.3 \\
\hline \multicolumn{5}{|c|}{ Passive Smoke Exposure } \\
\hline Yes & 21245 & 26.12 & 5073 & 30.25 \\
\hline No & 64668 & 73.88 & 12828 & 69.76 \\
\hline \multicolumn{5}{|l|}{ Caries } \\
\hline Yes & 15132 & 19.41 & 3748 & 22.79 \\
\hline No & 70781 & 80.59 & 14153 & 77.21 \\
\hline
\end{tabular}

Wt\%-Weighted percentage: Weighted percentages were obtained to control for complex sample design, therefore division of individual cell sizes by the total sample will not reflect weighted percentages.

$\mathrm{N}$-number of participants

FPL-Federal Poverty Level

Data Source: Child and Adolescent Health Measurement Initiative (CAHMI). DRC Indicator

Dataset: 2007 National Survey of Children's Health. Data Resource Center for Child and Adolescent Health, www.childhealthdata.org.

Table 1: Descriptive statistics 2007 National Survey of Children's Health.

\begin{tabular}{|c|c|c|c|c|c|}
\hline & \multicolumn{2}{|c|}{$\begin{array}{l}\text { Passive } \\
\text { Smoke } \\
\text { Exposure }\end{array}$} & \multicolumn{3}{|c|}{$\begin{array}{l}\text { No Passive Smoke } \\
\text { Exposure }\end{array}$} \\
\hline & $\mathrm{N}$ & $w t \%$ & $\mathrm{~N}$ & wt $\%$ & $p$-value \\
\hline \multicolumn{6}{|l|}{ Sex } \\
\hline Overall & & & & & 0.4254 \\
\hline Female & 7196 & 9.59 & 34044 & 39.13 & \\
\hline Male & 7921 & 9.8 & 36647 & 41.48 & \\
\hline SHCN & & & & & 0.1289 \\
\hline Female & 1601 & 9.86 & 5930 & 30.81 & \\
\hline Male & 2140 & 12.9 & 8212 & 46.44 & \\
\hline \multicolumn{6}{|l|}{ Race/ethnicity } \\
\hline Overall & & & & & $<.0001$ \\
\hline Non-Hispanic White & 9326 & 9.17 & 48853 & 47.36 & \\
\hline Non-Hispanic Black & 1671 & 2.92 & 6748 & 11.49 & \\
\hline Hispanic & 2494 & 5.66 & 8186 & 14.51 & \\
\hline Other & 1509 & 1.69 & 6259 & 7.21 & \\
\hline CSHCN & & & & & $<.0001$ \\
\hline Non-Hispanic White & 2387 & 11.93 & 10161 & 48.92 & \\
\hline Non-Hispanic Black & 458 & 3.75 & 1399 & 12.44 & \\
\hline Hispanic & 498 & 5.32 & 1298 & 10.03 & \\
\hline Other & 381 & 1.85 & 1165 & 5.75 & \\
\hline \multicolumn{6}{|l|}{ Age } \\
\hline Overall & & & & & $<.0001$ \\
\hline $0-5$ years & 2223 & 3.47 & 20360 & 25.78 & \\
\hline $6-11$ years & 6533 & 8.93 & 20971 & 25.51 & \\
\hline $12-17$ years & 6376 & 7.01 & 29450 & 29.3 & \\
\hline CSHCN & & & & & $<.0001$ \\
\hline $0-5$ years & 369 & 2.61 & 2633 & 16.04 & \\
\hline $6-11$ years & 1560 & 10.52 & 4583 & 28.14 & \\
\hline $12-17$ years & 1819 & 9.66 & 6937 & 33.03 & \\
\hline \multicolumn{6}{|c|}{ Household highest education } \\
\hline Overall & & & & & $<.0001$ \\
\hline Less than high school & 1380 & 2.62 & 3599 & 6.32 & \\
\hline High school graduate & 2858 & 5.76 & 19403 & 17.53 & \\
\hline More than high school & 10187 & 10.87 & 54380 & 56.89 & \\
\hline CSHCN & & & & & $<.0001$ \\
\hline Less than high school & 283 & 2.94 & 644 & 6 & \\
\hline High school graduate & 746 & 6.29 & 2032 & 16.13 & \\
\hline More than high school & 2459 & 13.37 & 10812 & 55.27 & \\
\hline \multicolumn{6}{|l|}{ Household income } \\
\hline Overall & & & & & $<.0001$ \\
\hline Less than $100 \% \mathrm{FPL}$ & 2600 & 5.04 & 7457 & 13.23 & \\
\hline 100-199\% FPL & 3046 & 4.84 & 11544 & 16.04 & \\
\hline 200-399\% FPL & 5063 & 5.41 & 23992 & 25.81 & \\
\hline $400 \%$ and above FPL & 4423 & 4.11 & 27788 & 25.51 & \\
\hline CSHCN & & & & & $<.0001$ \\
\hline Less than $100 \% \mathrm{FPL}$ & 743 & 6.77 & 1655 & 13.39 & \\
\hline 100-199\% FPL & 839 & 5.49 & 2262 & 15.29 & \\
\hline $200-399 \%$ FPL & 1126 & 5.96 & 4694 & 24.62 & \\
\hline $400 \%$ and above FPL & 1040 & 4.57 & 5542 & 23.92 & \\
\hline \multicolumn{6}{|l|}{ Medication use } \\
\hline Overall & & & & & 0.5208 \\
\hline Yes & 423 & 0.44 & 1477 & 1.6 & \\
\hline No & 13757 & 19.92 & 61696 & 78.04 & \\
\hline
\end{tabular}


Citation: Wiener RC (2013) Children with Special Health Care Need's Association of Passive Tobacco Smoke Exposure and Dental Caries: 2007 National Survey of Children's Health. J Psychol Abnorm Child 2: 104. doi:10.4172/2329-9525.1000104

Page 4 of 5

\begin{tabular}{|l|l|l|l|l|l|}
\hline CSHCN & & & & & 0.7307 \\
\hline Yes & 333 & 1.98 & 1108 & 7.03 & \\
\hline No & 2540 & 20.72 & 9937 & 70.28 & \\
\hline Asthma & & & & & \\
\hline Overall & & & & & $<.0001$ \\
\hline Yes & 2440 & 3.38 & 9349 & 10.96 & \\
\hline No & 12666 & 16 & 61356 & 69.66 & \\
\hline CSHCN & & & & & 0.5383 \\
\hline Yes & 1424 & 9.12 & 5267 & 29.77 & \\
\hline No & 2320 & 13.69 & 8857 & 47.41 & \\
\hline Allergies & & & & & \\
\hline Overall & & & & & 0.1843 \\
\hline Yes & 3070 & 3.55 & 13127 & 13.81 & \\
\hline No & 12026 & 15.87 & 57528 & 66.77 & \\
\hline CSHCN & & & & & 0.672 \\
\hline Yes & 1482 & 8.78 & 5630 & 28.92 & \\
\hline No & 2257 & 14.06 & 8483 & 48.24 & \\
\hline Passive Smoke exposure & & & & & \\
\hline Overall & & & & & $<.0001$ \\
\hline Yes & 4635 & 6.07 & 16610 & 20.05 & \\
\hline No & 10497 & 13.34 & 54171 & 60.54 & \\
\hline CSHCN & & & & & $<.0001$ \\
\hline Yes & 1322 & 8.05 & 3751 & 22.2 & \\
\hline No & 2426 & 14.74 & 10402 & 55.01 & \\
\hline Wo: & & & & \\
\hline
\end{tabular}

$\mathrm{Wt} \%$ : Weighted percentage. Weighted percentages were obtained to control for complex sample design, therefore division of individual cell sizes by the total sample will not reflect weighted percentages.

Significant group differences were tested by Chi-square statistics (Rao-Scott ChiSquare p-values)

Data Source: Child and Adolescent Health Measurement Initiative (CAHMI). DRC Indicator

Dataset: 2007 National Survey of Children's Health. Data Resource Center for Child and Adolescent Health, www.childhealthdata.org.

Table 2: Chi square analyses for caries versus variables of interest 2007 National Survey of Children's Health. with caries in pre-school children in an adjusted analysis including socioeconomic status, diet/nutritional status, and confectionery spending [21]. Additionally, in a study of young children, the decayed, missing, and filled teeth indices were higher with children having a higher salivary cotinine level (the biomarker for passive tobacco smoke exposure) than young children who did not have a high salivary cotinine level [9].

The results of the adjusted model indicate that the relationship is attenuated, but remains significant with an adjusted odds ratio of 1.23 (95\% Confidence Interval 1.02, 1.50; $\mathrm{p}=0.0352$ ). Although not the primary focus of this study, the relationship between passive smoke and all children also showed an independent association in both the unadjusted and adjusted models. CSHCN were more likely, in general, to have a higher odds of caries than children overall, with an adjusted odds ratio of 1.22 (95\% Confidence Interval 1.09, 1.36; $\mathrm{p}=0.0003$ ).

Other researchers have suggested potential mechanisms by which tobacco exposure may be related to caries. These include predisposition of children to infection through changes to the immune system, nicotine inhibition of phagocytic activity in neutrophils and monocytes, and lowered amount and buffering capacity of saliva [13] Cigarette smoke condensates from sidestream smoke (passive exposure) were found to suppress macrophage responsiveness to interferon, although the potential effects on the host's defenses systemically and orally were undetermined [22]. As noted previously, decreased Vitamin C levels in children exposed to passive smoke were associated with decreased immune function and Streptococcus Mutans growth [16]. Additionally, passive smoke exposure (as measured by salivary cotinine levels) has been associated with decreased secretory IgA--the concentration of secretory IgA is lower in infection-prone children, and secretory IgA is involved in a complex relationship with the aggregation of bacteria and dental caries [23].

\begin{tabular}{|c|c|c|c|c|}
\hline & \multicolumn{2}{|c|}{ All children } & \multicolumn{2}{|c|}{ CSHCN } \\
\hline & Odds (95\% Cl) Ratios & $\mathrm{p}$-value & Odds $(95 \% \mathrm{Cl})$ Ratios & $p$-value \\
\hline \multicolumn{5}{|l|}{ Unadjusted } \\
\hline Passive smoke exposure & $1.37(1.23,1.52)$ & $<.0001$ & $1.35(1.13,1.62)$ & 0.0011 \\
\hline \multicolumn{5}{|l|}{ Adjusted } \\
\hline Passive Smoke exposure & $1.27(1.14,1.41)$ & $<.0001$ & $1.23 \quad(1.02,1.50)$ & 0.0352 \\
\hline \multicolumn{5}{|l|}{ Race/ethnicity } \\
\hline Non-Hispanic White & 1.00 (reference) & & 1.00 (reference) & \\
\hline Non-Hispanic Black & $1.08(0.96,1.22)$ & 0.0085 & $1.00(0.78,1.27)$ & 0.0214 \\
\hline Hispanic & $1.75(1.05,1.32)$ & $<.0001$ & $1.90(1.38,2.60)$ & 0.004 \\
\hline Other & $1.20(1.02,1.41)$ & 0.6967 & $1.27(0.94,1.71)$ & 0.8734 \\
\hline \multicolumn{5}{|l|}{ Age } \\
\hline $0-5$ & 1.00 (reference) & & 1.00 (reference) & \\
\hline $6-11$ & $2.66(2.32,3.05)$ & $<.0001$ & $2.40(1.77,3.24)$ & $<.0001$ \\
\hline $12-17$ & $1.86(1.62,2.14)$ & 0.0095 & $1.97(1.46,2.65)$ & 0.0198 \\
\hline \multicolumn{5}{|l|}{ Household income } \\
\hline Less than $100 \% \mathrm{FPL}$ & $1.91(1.64,2.22)$ & $<.0001$ & $2.27(1.69,3.05)$ & $<.0001$ \\
\hline 100-199\%FPL & $1.65(1.44,1.90)$ & 0.0002 & $1.75(1.33,2.31)$ & 0.0294 \\
\hline 200-399\%FPL & $1.22(1.09,1.38)$ & 0.0002 & $1 / 18(0.90,1.54)$ & 0.0058 \\
\hline CSHCN & $1.22(1.09,1.36)$ & 0.0003 & & \\
\hline
\end{tabular}

Data Source: Child and Adolescent Health Measurement Initiative (CAHMI). DRC Indicator

Dataset: 2007 National Survey of Children's Health. Data Resource Center for Child and Adolescent Health, www.childhealthdata.org.

Table 3: Logistic regression odds ratios and adjusted odds ratios for caries and passive smoke exposure: 2007 National Survey of Children's Health. 


\section{Study Limitations}

However, it should also be noted that this study's results are associations and do not necessarily assume a causal relationship. There could be confounding due to diet, and oral hygiene which were not measured in this study. It is possible that smoking during pregnancy increased the potential for childhood illness, immune system compromise, and enamel hypoplasia, and ultimately caries rather than current exposure to passive smoke [24]. However, in this study, the increase in odds of recent caries and passive smoke were determined not only in pre-school children, but also in school aged children and teenagers who would have mixed dentitions and permanent dentitions as the sample included children ages $0-17$. Distinctions were not made between secondhand and third hand smoke exposure nor the number of cigarettes to which a child was exposed or length of time of such exposure in this study. However the study did involve current exposure and current report of caries. There may have been misclassification of tobacco use and presence of caries due to social desirability bias of the telephone respondents. Such biases would potentially have resulted in more responses of no use of tobacco than actually occurred, and fewer reports of caries than actually occurred. Such biases would have attenuated the results or biased the results to the null. Caries experience within the previous 6 months may also have been subject to recall bias. Such a bias would be expected to be non-differential.

\section{Study Strengths}

This was a study based on data from the large, Nation Survey of Children's Health which has been sponsored by the Maternal and Child Health Bureau of the Department of Health and Human Services. The survey was supervised for data integrity by the National Center for Health Statistics in the Centers for Disease Control and Prevention. Data analysis accounted for weighting which improved result precision. The results are consistent with other research. There is theoretical biologic plausibility of the hypothesis.

\section{Conclusion}

The results of this cross-sectional study indicate an association of recent caries and passive tobacco smoke in CSHCN ages 0-17 years. Additional research is needed in a cohort study to determine a true causal association.

\section{Acknowledgement}

Research reported in this article was supported by the National Institute of General Medical Sciences of the National Institutes of Health under Award Number U54GM104942. The content is solely the responsibility of the authors and does not necessarily represent the official views of the National Institutes of Health.

\section{References}

1. McPherson M, Arango P, Fox H, Lauver C, McManus M, et al. (1998) A New Definition of Children with Special Health Care Needs. Pediatrics.102:137-139.

2. Ghandour RM, Grason HA, Schempf AH, Strickland BB, Kogan MD, et al (2013) Healthy people 2010 leading health indicators: how children with special health care needs fared. Am J Public Health 103: e99-99e106.

3. Lutenbacher M, Karp SM, Dietrich MS, Sullivan JN (2013) Are services to tennessee children with special health care needs comparable with national achievement of MCHB objectives? Public Health Nurs 30: 7-17.

4. Health and Human Services. Cancer progress report: Second hand smoke and cancer, 2003.

5. Ballantyne C. (2009) What is third-hand smoke? Is it dangerous? Scientific American. 9:130

6. Aligne CA, Moss ME, Auinger P, Weitzman M (2003) Association of pediatric dental caries with passive smoking. JAMA 289: 1258-1264.

7. Leroy R, Hoppenbrouwers K, Jara A, Declerck D (2008) Parental smoking behavior and caries experience in preschool children. Community Dent Ora Epidemiol 36: 249-257.

8. Shenkin JD, Broffitt B, Levy SM, Warren JJ (2004) The association between environmental tobacco smoke and primary tooth caries. J Public Health Dent 64: $184-186$

9. AvĀŸar A, Darka O, TopaloÄŸlu B, Bek Y (2008) Association of passive smoking with caries and related salivary biomarkers in young children. Arch Oral Biol 53: 969-974.

10. Hanioka T, Nakamura E, Ojima M, Tanaka K, Aoyama H (2008) Dental caries in 3 -year-old children and smoking status of parents. Paediatr Perinat Epidemio 22: 546-550.

11. Tanaka K, Miyake Y, Sasaki S (2009) The effect of maternal smoking during pregnancy and postnatal household smoking on dental caries in young children. J Pediatr 155: 410-415.

12. Ayo-Yusuf OA, Reddy PS, van Wyk PJ, van den Borne BW (2007) Household smoking as a risk indicator for caries in adolescents' permanent teeth. J Adolesc Health 41: 309-311.

13. Tanaka K, Miyake Y, Arakawa M, Sasaki S, Ohya Y (2010) Household smoking and dental caries in schoolchildren: the Ryukyus Child Health Study. BMC Public Health 10: 335.

14. Fujinami Y, Nakano K, Ueda O, Ara T, Hattori T, et al. (2011) Dental caries area of rat molar expanded by cigarette smoke exposure. Caries Res 45: 561-567.

15. Benedetti G, Campus G, Strohmenger L, Lingström P (2013) Tobacco and dental caries: a systematic review. Acta Odontol Scand 71: 363-371.

16. Hanioka T, Ojima M, Tanaka K, Yamamoto M (2011) Does secondhand smoke affect the development of dental caries in children? A systematic review. Int J Environ Res Public Health 8: 1503-1519.

17. Hugoson A, Hellqvist L, Rolandsson M, Birkhed D (2012) Dental caries in relation to smoking and the use of Swedish snus: epidemiological studies covering 20 years (1983-2003). Acta Odontol Scand 70: 289-296.

18. Tanaka K, Hanioka T, Miyake Y, Ojima M, Aoyama H (2006) Association of smoking in household and dental caries in Japan. J Public Health Dent 66: 279-281.

19. Vellappally S, Fiala Z, Smejkalová J, Jacob V, Shriharsha P (2007) Influence of tobacco use in dental caries development. Cent Eur J Public Health 15 116-121.

20. Important Information: DRC Indicator Data Set for the $2007 \mathrm{NSCH}$.

21. Williams SA, Kwan SY, Parsons S (2000) Parental smoking practices and caries experience in pre-school children. Caries Res 34: 117-122.

22. Edwards K, Braun KM, Evans G, Sureka AO, Fan S (1999) Mainstream and sidestream cigarette smoke condensates suppress macrophage responsiveness to interferon gamma. Hum Exp Toxicol 18: 233-240.

23. AvÅŸar A, Darka O, Bodrumlu EH, Bek Y (2009) Evaluation of the relationship between passive smoking and salivary electrolytes, protein, secretory $\lg A$ sialic acid and amylase in young children. Arch Oral Biol 54: 457-463.

24. Davies M (2003) Passive smoking and dental caries in children. JAMA 289 2940. 